九州大学学術情報リポジトリ

Kyushu University Institutional Repository

\title{
Heterogeneity of dnaB Locus of Mycobacterium avium-intracellulare Complex
}

\section{Yamamoto, Kohj i}

Laboratory of Insect Genetic Resources, Division of Applied Genetic Resources, Department of Genetic Resources Technology, Graduate School of Bioresoruce and Bioenvironmental

Sciences, Kyushu University

\section{Rutherford, Stacey A}

Biomedical Research, The University of Texas Health Center at Tyler

Rajagopalan, Malini

Biomedical Research, The University of Texas Health Center at Tyler

Hirakawa, Hideki

Laboratory of Mplecular Gene Technics, Division of Molecular Gene Technics, Departmant of Genetic Resources Technology, Graduate School of Bioresource and Bioenvironmental Sciences, Kyushu University

他

https://doi.org/10.5109/4599

出版情報：九州大学大学院農学研究院紀要. 49 (2)，pp. 375-381，2004-10-01. Faculty of Agriculture, Kyushu University

バージョン：

権利関係 : 


\title{
Heterogeneity of dnaB Locus of Mycobacterium avium-intracellulare Complex
}

\author{
Kohji YAMAMOTO' ${ }^{*}$, Stacey A. RUTHERFORD ${ }^{2}$, Malini RAJAGOPALAN ${ }^{2}$, \\ Hideki HIRAKAWA ${ }^{3}$, Satoru KUHARA ${ }^{4}$, Yutaka BANNO, \\ Hiroshi FUJII and Murty V.V.S. MADIRAJU²
}

\author{
Laboratery of Insect Genetic Resources, Division of Applied Genetic Resources, \\ Department of Genetic Resources Technology, Faculty of Agriculture, \\ Kyushu University, Fukuoka 812-8581, Japan \\ (Received June 29, 2004 and accepted July 13, 2004)
}

\begin{abstract}
Analysis of the dnaB gene, homologue of the Escherichia coli replicative DNA helicase DnaB, from various Mycobacterium intracellulare complex strains revealed their dnaB genes were heterogeneity. We found that intein was included in-frame in the dnaB locus of $M$. intracellulare and that the intein is highly similar to $M$. avium intein. Phylogenetic study showed intein sequences were remote from their own host, dnaB sequences and suggested that the horizontal transfer had occurred among Mycobacterium avium-intracellulare complex strains.
\end{abstract}

\section{INTRODUCTION}

The Mycobacterium avium-intracellulare complex (MAC) group of organisms is one of the most common causes of mycobacterial lung disease (Wallace et al., 1994). Routine clinical laboratory testing of MAC organisms does not differentiate between M. intracellulare and M. avium (Wallace et al., 1994). In the genus Mycobacterium, pathogens such as MAC, $M$. tuberculosis, $M$. bovis and $M$. leprae are slow growers and non-pathogens such as $M$. smegmatis and $M$. fortuitum are rapid growers. However, the genetic and biochemical basis for the differences in the growth rates between different mycobacteria and the key aspects of their respective cell cycle including DNA replication are largely unknown. When we studied on DnaB function involved in DNA replication, we found that the dnaB locus of $M$. intracellulare (MI1442) contained intein. Intein is a protein sequence that is inserted in-frame within the precursor protein and is excised during posttranslational maturation, so-called protein splicing, from the precuesor pro-

1 Laboratory of Insect Genetic Resources, Division of Applied Genetic Resources, Department of Genetic Resources Technology, Graduate School of Bioresource and Bioenvironmental Sciences, Kyushu University

2 Biomedical Research, The University of Texas Health Center at Tyler, 11937 US Highway @ 271, Tyler, TX 75708-3154, U.S.A.

3. Laboratory of Molecular Gene Technics, Division of Molecular Gene Technics, Department of Genetic Resources Technology, Graduate School of Bioresource and Bioenvironmental Sciences, Kyushu University

4 Laboratory of Molecular Gene Technics, Division of Molecular Gene Technics, Department of Genetic Resources Technology, Faculty of Agriculture, Kyushu University

* Correspondence author (E-mail: yamamok@agr.kyushu-u.ac.jp) 
tein. Protein splicing is associated with the ligation of exteins, the flanking regions of the inteins, and is essential to regenerate functional host protein intein (Perler, 2000). Many inteins contain endonuclease domain, which exhibit homing activity. The endonuclease is thought to be participated in gene mobility of intein coding sequences into inteinless alleles (Gimble, 2000). However, not much is available on gene mobility of intein, therefore, it is necessary to characterize intein of MAC strains. In this report, we described sequencing of intein from $M$. intracellulare and the alignment analyses of intein sequences from other Mycobacteria. Furthermore, we discussed the possibility that intein is a horizontal transfer by using phylogenetic study.

\section{MATERIALS AND METHODS}

\section{Strains}

M. avium MAC104 was obtained from Dr Luiz Bermudez at Kuzell Institute, San Francisco, USA. M. intracellulare $\mathrm{mc}^{2}-76$ was from Dr Raul Barletta at University of Nebraska, Lincoln, USA. M. avium ATCC35712, M. avium MA1313, M. intracellulare strains MI1149, MI1442, MI1522, were obtained from Dr. Richard J. Wallace, Jr., UTHCT, Tyler, TX and $M$. avium A5 was provided from Dr. Robert Husson, Children's Hospital, Boston, MA.

\section{PCR amplification, cloning and sequencing}

To amplify dnaB region, oligodeoxyribonucleotide (oligo) primers based on the 5 ' and 3 ' ends of $M$. tuberculosis dnaB sequence were used in PCR with genomic DNA from mycobacterial strains. The NdeI site was incorporated for cloning the dnaB into expression vectors. PCR was performed under the following conditions: $95^{\circ} \mathrm{C}$ for $5 \mathrm{~min} ; 30$ cycles of $94^{\circ} \mathrm{C}(1 \mathrm{~min}), 60^{\circ} \mathrm{C}(1 \mathrm{~min})$, and $72^{\circ} \mathrm{C}(2.5 \mathrm{~min})$, and final extension of $72^{\circ} \mathrm{C}(10 \mathrm{~min})$, then held at $4^{\circ} \mathrm{C}$. PCR products were electrophoresed on a $1 \%$ agarose gel, stained eith ethidium bromide and visualized under ultraviolet light. Amplified DNAs were cloned into pGEM-T vector (Promega) and sequenced with the ABI dye terminator cycle sequencing kit with AmpliTaq DNA polymerase in the ABI377 sequencer (Perkin-Elmer Applied Biosystem). The dnaB sequences of $M$. avium ATCC35712, $M$. intracellulare $\mathrm{mc}^{2}-76$, and MI1442 were deposited in GenBank under Accession Nos. AF259901, AF259900, and AF307984, respectively. Preliminary sequence data of $M$. smegmatis was obtained from The Institute for Genomic Research website at http://www.tigr.org.

\section{RESULTS AND DISCUSSION}

\section{Cloning and sequencing of dnaB of $M$. intracellulare}

To investigate the presence of intein sequences in the dnaB genes of MAC strains, the synthetic primers based on conserved sequence around intein insertion site in the dnaB gene were used in PCR. The sizes of PCR products with $2.5 \mathrm{~kb}$ (Fig. 1, lanes $2 \sim 5,8$ ) and $1.4 \mathrm{~kb}$ (Fig: 1, lanes 7, 9 and 10) were detected, indicating that the dnaB locus in one of the four strains of $M$. intracellulare strains (MI1442) harbors intein, whereas all strains of $M$. avium strains (ATCC35712, A5, MAC104 and MA1313) contained intein. Southern hybridization with dnaB-specific probes confirmed the identity of the PCR products (data 


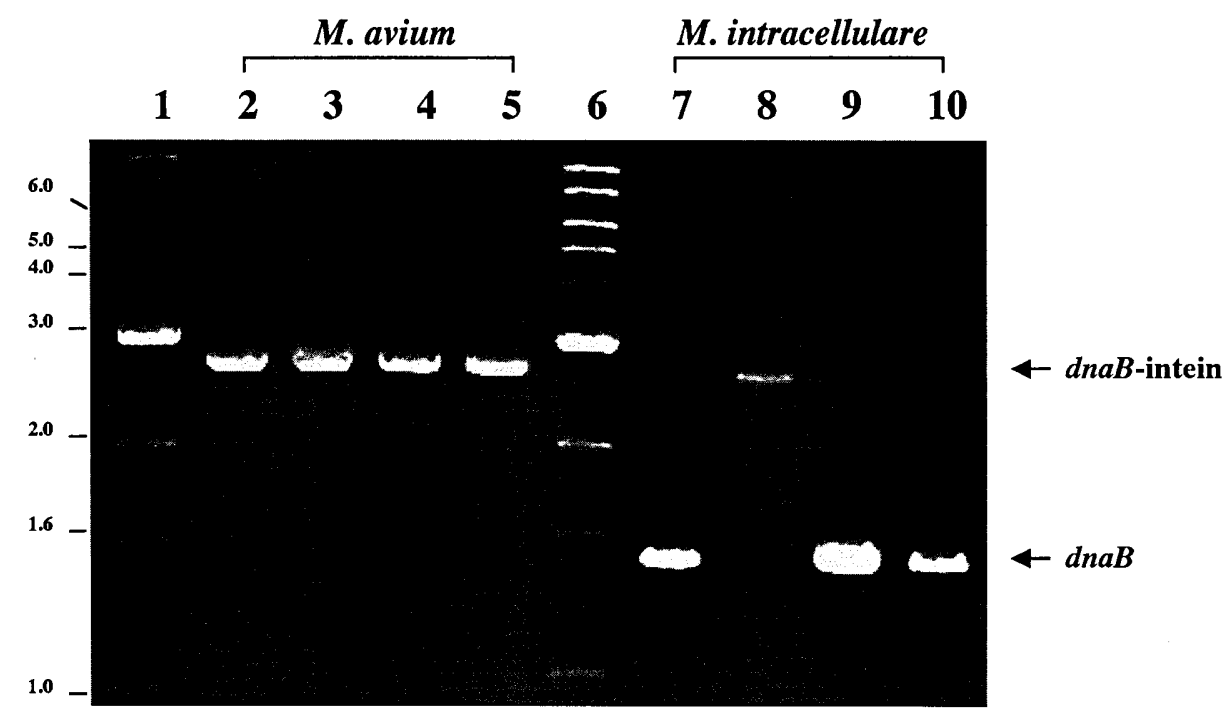

Fig. 1. Heterogeneity of the dnaB locus of MAC strains.

PCRs of genomic DNAs from different strains of MAC were performed. Lanes: 2-5: $M$. avium group; 7-10: $M$. intracellulare group; lanes 1 and 6 are 1-kb ladder. (2) M. avium (MA) ATCC35712; (3) MA104; (4) MA A5 and (5) MA1313; (7) M. intracellulare (MI) 1149; (8) MI1442; (9) MI1522 and (10) MI mc ${ }^{2}-76$. Arrows indicate that locations of dnaB with and without intein.

not shown). To verify that the PCR products prepared from $M$. intracellulare MI 1442 genomic DNA are related to intein, the $\mathrm{dnaB}$ region was cloned and sequenced. The nucleotide sequence analysis indicated the presence of $1002 \mathrm{bp}$ DNA fragment and corresponded to an insertion of 334 amino acid long polypeptide (Fig. 2). We detected that the $M$. intracellullare sequence consists of Blocks A, N2, B, N4, F and G for splicing motif and contains several intein-specific sequence motifs designated as Blocks C, D, E and $\mathrm{H}$, that are responsible for homing activities (Fig. 2) (Fsihi et al., 1996; Pietrokovski, 1998). It also contains other several intein-specific sequence such as conserved C-terminal splice site $-\mathrm{H}-\mathrm{N}-\mathrm{S}-$ and putative dodecapeptide domain LAGLIDADG. A notable feature of the MAC DnaB inteins is that the intein N-terminal amino acid is Ala as opposed to Cys in M. tuberculosis and Ser in others (Perler, 2000). The two other families of inteins that start with Ala were discovered in the K1bA proteins and the Snf2 helicase (Perler, 2000). As shown in Fig. 2, $M$. intracellulare intein is $89 \%$ homology to $M$. avium. The DnaB inteins are related, although $M$. leprae and $M$. smegmatis inteins are missing the center region. These results indicate that identical intein is acquired in the dnaB locus of the MAC group strains.

\section{Phylogenetic distribution of inteins}

Inteins are thought to be mobile genetic elements. Homing endonuclease encoded in 


\section{Leprae \\ M. smegmatis M.intra \\ M.avium}

\section{Leprae}

M.smegmatis

M.intra

M.avium

\section{Leprae \\ M.smegmatis \\ M. intra \\ M.avium}

\section{Leprae \\ M.smegmatis \\ M.intra \\ M.avium}

M. Ieprae
M.smegmatis
M.intra
M.avium

M. leprae

M. smegmatis

M. intra

M. avium

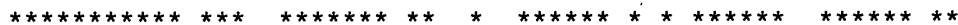

ALALDTPLPTPTGWTAMGDVAVGDELLAVDEAPTRVVAATEVMLGRPCYEIEFSDGTVIV ALALDTPLPTPSGWTTMGDVAVGDHLLGPDGEPTRVVADTDVMLGRPCYVVEFSDGTAIV ALALDTPLPTPTGWTTTGDVAVGDELLGADGKPTRVVAATEVLLGRPCYEVEFSDGTVIV ALALDTPLPTPTGWTTMGDVAVGDELLGDDGRPTRVVAATDVMLGRPCYEVEFSDGTVIV

$* * * * * * *$

ADAQHQWPTSY

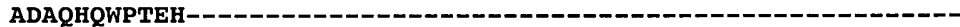

ADAAHQWLTETRASRKSAQAAAAGYNRYKNQRTFAAVRTTAEIAGTLRCPTLDRRLNHSV ADAAHQWLTETRVSRKSAQAAAVGYNRYKNQRTFAAVRTTAEIAETLRCPAQDRRLNHSV

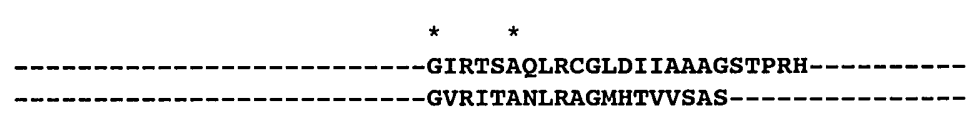
VNARALDLPDREFLVPPYTLGAWLGDGTSAAAQITAADPEI IMRIEAEMS-STVGTLQAR VNARALELPDREFLVPPYTLGAWLGDGTSAAAQITAADPEI IMRIEAEDSGAGVGTLQAR Block C

Fig. 2. Alignment of intein sequences of $M$. avium, $M$. intracellulare, $M$. leprae and $M$. smegmatis Deduced intein sequences were aligned using ClustalW multiple sequence analysis. Asterisks represent identical amino acids. Gaps in the sequences are shown as dashed lines. Conserved intein signature motif domains are underlined and are marked as C, D, E and H. Domains C and E represent putative dodecapeptide conserved domains LAGLIDADG.

intein initiates intein gene transfer to intein-less gene. In case of MAC intein, it is reasonable to propose that the dnaB-associated intein should also behave as a homing endonuclease, based on the highly conserved structural features and sequence homologies with homing endonuclease. As shown in Fig. 3, phylogenetic tree was generated from aligned sequences of three exteins and inteins in dnaB genes. Phylogenetic analysis revealed that the DnaB and inteins were separated into different groups. $M$. intracellulare intein was blanched in same group with $M$. avium and $M$. leprae inteins. Another group was generated by dnaB sequences of $M$. intracellulare, $M$. avium and $M$. leprae and was distinct from the group of intein sequences, suggesting that homing activity is believed to mediate the transposition of an intein to an intein-less allele. 


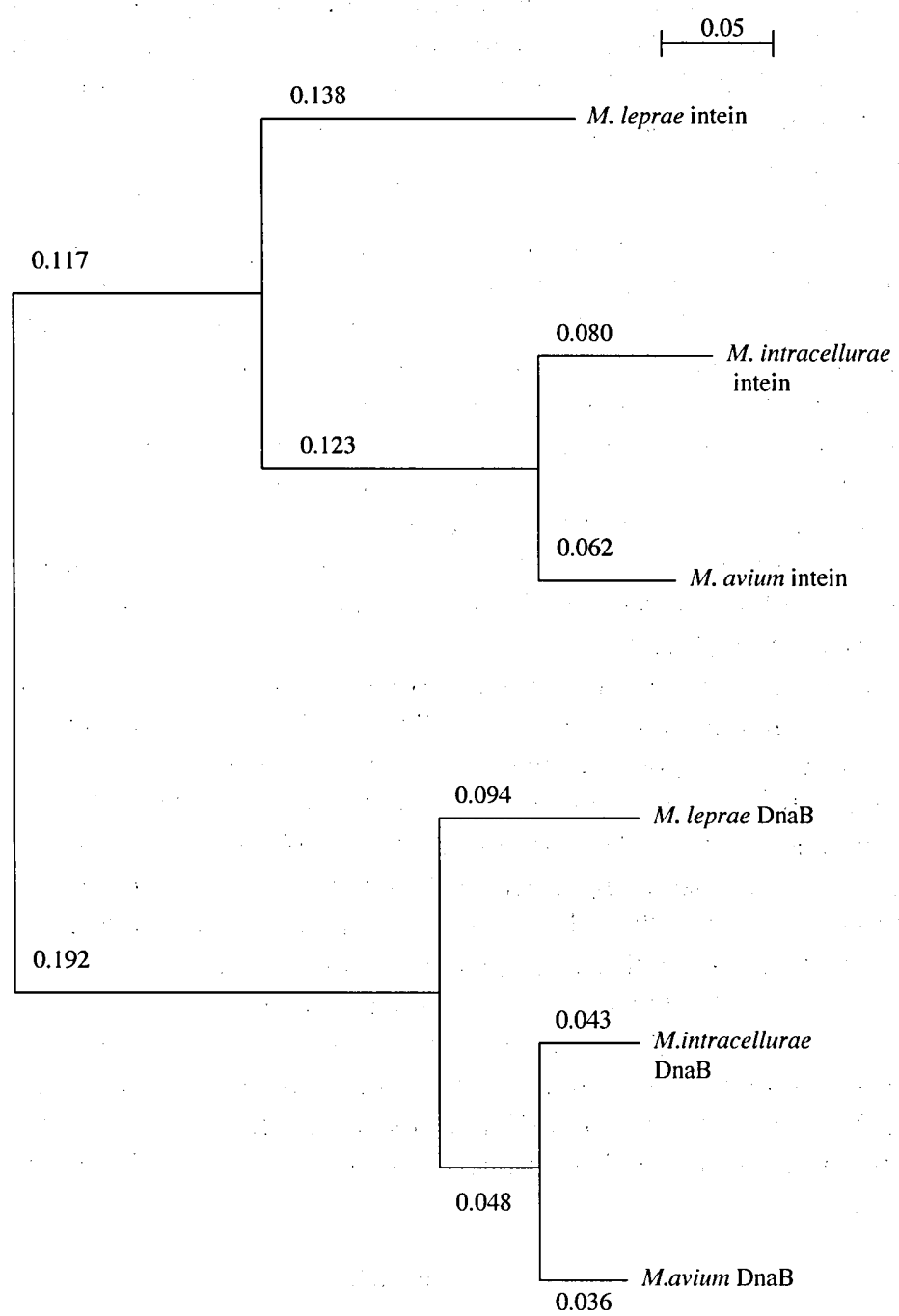

Fig. 3. Phylogenetic tree of the sequences of intein and extein in dnaB genes.

Phylogenetic tree was built upon the alignment of nucleotide sequences of intein and extein in dnaB genes which were sequenced in this study and obtained from the GenBank database, using ClustalW. The tree-building method based on Neighbour-joining was performed by the NJplot software. Numbers attached to nodes represents branch length.

The restriction sites for homing endonuclease in mycobacterium dnaB genes

With comparison of the extein insertion sites, we found that the location of this fragment is in exactly the same location (GVGK-STLGLD) in M. avium ATCC35712, $M$. leprae and $M$. smegmatis but differs in $M$ : tuberculosis at the same location 
(RESG-SLEG) as that found in Synechocystis spp., the thermophile Rhodothermus marinus and plant chloroplast Porphyrus purpurea (Fsihi et al., 1996; Pietrokovski, 1998). The sequences of insertion site in the $M$. avium MAC104 and A5 dnaB genes are also found to be identical to the corresponding sequence of $M$. avium ATCC35712 and $M$. intracellulare MI1442. When the nucleotide sequences of insertion sites are aligned with those of dnaB genes from $M$. intracellulare, $M$. avium, $M$. leprae and $M$. smegmatis, we found that the Lys codon corresponding to the site of insertion was AAA in $M$. intracellulare dnaB gene that reveals heterogeneity, whereas this was AAG in three of the four species harboring inteins (Fig. 4). It suggests that the corresponding homing endonuclease could recognize particular sequence and represent sequence specificity. It was also shown that the Tyr codon corresponding to the site of insertion was TAC in all gyrA genes that did not contain the intein coding sequence, whereas in three of the four species harboring inteins this was TAT in case of mycobacterial gyrA genes (Perler et al., 1997). Taken together, distinction of the nucleotide sequences of the insertion sites might account for the heterogeneity, because the presence of active endonuclease motifs in $M$. intracellulare and $M$. avium dnaB inteins indicate that the MAC intein could exhibit endonuclease activity (Fig. 2).

Organisms have chance to acquire inteins. For example, plasmid and virus could carry foreign DNA to them and gene conversion, DNA repair and recombination could be occurred. In case of MAC, it is possible that recombinational events such as conjugation and transduction contribute to homing events. Conjugation is thought to be the primary route for horizontal gene transfer (Parsons et al., 1998). MAC group strains are difficult to transform presumably because many of these strains contain multiple plasmids and or cryptic phages (Crawford et al., 1981). It is conceivable that these plasmids harbor activities that mediate gene transfer leading to acquisition of intiens. The polyclonal nature of MAC infections (Wallace et al., 1998), cell-cell contacts and Hfr conjugation in mycobacteria (Parsons et al., 1998) are consistent with the above reason. The roles, if any, of intein in $M$. avium metabolism are unknown as inteins are often perceived as selfish genetic elements. The heterogeneity in MAC dnaB locus does not favor any advantageous roles for inteins to the host, although it is important to note that all $M$. avium strains
intein insertion site
M. intracellulare
M. avium
M. leprae
M. smegmatis

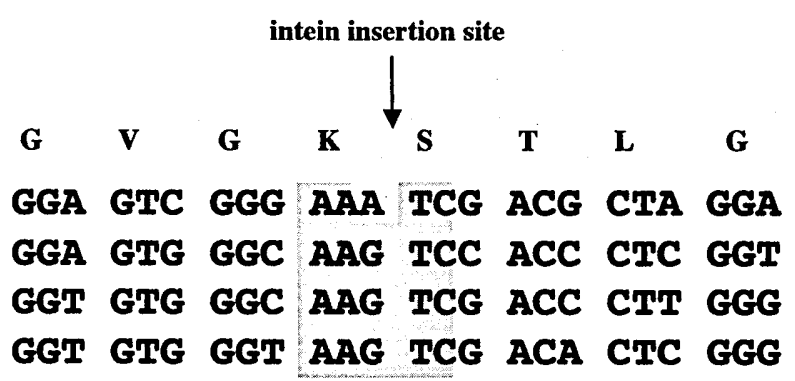

Fig. 4. Alignment of nucleotide sequences of the restriction sites in mycobacterial dnaB genes. Sequences were from alleles from dnaB genes of $M$. intracellulare, $M$. avium, $M$. leprae and $M$. smegmatis. Deduced DnaB sequence is shown above and arrow indicates intein insertion site: Conserved nucleotides in the insertion site are shaded. 
examined appeared to contain intein in the dnaB gene and the majority of the MAC infections in AIDS patients are primarily due to M. avium (De smet et al., 1996). The replicative helicase DnaB protein plays a crucial role in the DNA replication process in Escherichia coli (Biswas and Biswas, 1999). Assuming that the M. avium DnaB precursor protein undergoes splicing in vivo to produce functional DnaB protein, as in other intein containing precursor proteins, then it is possible to envision that the rate with which the DnaB protein is formed following splicing could influence the rate of $M$. avium DNA replication process affecting both intracellular and extracellular growth.

\section{REFERENCES}

Biswas, E. E. and S. B. Biswas 1999 Mechanism of DnaB helicase of Escherichia coli: Structural domains involved in ATP hydrolysis, DNA binding and oligomerization. Biochemistry, 38: 10919-10928

Crawford, J. T., D. M. Cave and J. H. Bates 1981 Characterization of plasmids from strains of Mycobacterium avium-intracellulare. Rev. Infect. Dis., 3: 949-952

De Smet, K. A. L., T. J. Heller, A. W. Kahn, I. N. Brown and J. Ivanyi 1996 Genetic and serovar typing of clinical isolates of the Mycobacterium avium-intracellulare complex. Tuber. Lung Dis., 77(1): $71-76$

Fsihi, H., V. Vincent and S. T. Cole 1996 Homing events in the gyrA gene of some mycobacteria. Proc. Natl. Acad. Sci. USA, 93: 3410-5

Parsons, L. M., C. S. Jankowski and K. M. Derbyshire 1998 Conjugal transfer of chromosomal DNA in Mycobacterium smegmatis. Mol. Microbiol., 28: 571-582

Perler, F. B. 2000 InBase, the Intein Database. Nucleic Acids Res., 28: 344-5

Perler, F. B., G. J. Olsen and E Adam 1997 Compilation and analysis of intein sequences. Nucleic Acids Res., 25: 1087-93

Pietrokovski, S. 1998 Modular organization of inteins and C-terminal autocatalytic domains. Protein Sci., 7: 64-71

Yamamoto, K., B. Low, A. S. Rutherford, M. Rajagopalan and M. Madiraju 2001 The Mycobacterium avium-intracellulare complex dnaB locus and protein intein splicing. Biochem. Biophys. Res. Commun., 280: 898-903

Wallace, R. J. Jr., B. A. Brown, D. E. Griffith, W. M. Girard, D. T. Murphy, G. O. Onyi, V. A. Steingrube and G. H. Mazurek 1994 Initial clarithromycin monotherapy for Mycobacterium avium-intracellulare complex lung disease. Am. J. Respir. Crit. Care Med., 149: 1335-1341

Wallace, R. J. Jr., Y. Zhang, B. A. Brown, D. Dawson, D. T. Murphy, R. Wilson and D. E. Griffith 1998 Polyclonal Mycobacterium avium complex infections in patients with nodular bronchiectasis. Am J Respir Crit Care Med., 158(4): 1235-44 